\title{
Optical and electrical properties of polycrystalline and amorphous Al-Ti thin films
}

Canulescu, Stela; Borca, C. N.; Rechendorff, Kristian; Daviðsdóttir, Svava; Pagh Almtoft, K.; Nielsen, L. P.; Schou, Jørgen

Published in:

Applied Physics Letters

Link to article, DOI:

$10.1063 / 1.4945769$

Publication date:

2016

Document Version

Publisher's PDF, also known as Version of record

Link back to DTU Orbit

Citation (APA):

Canulescu, S., Borca, C. N., Rechendorff, K., Daviơsdóttir, S., Pagh Almtoft, K., Nielsen, L. P., \& Schou, J. (2016). Optical and electrical properties of polycrystalline and amorphous Al-Ti thin films. Applied Physics Letters, 108(14), [141909]. https://doi.org/10.1063/1.4945769

\section{General rights}

Copyright and moral rights for the publications made accessible in the public portal are retained by the authors and/or other copyright owners and it is a condition of accessing publications that users recognise and abide by the legal requirements associated with these rights.

- Users may download and print one copy of any publication from the public portal for the purpose of private study or research.

- You may not further distribute the material or use it for any profit-making activity or commercial gain

- You may freely distribute the URL identifying the publication in the public portal 


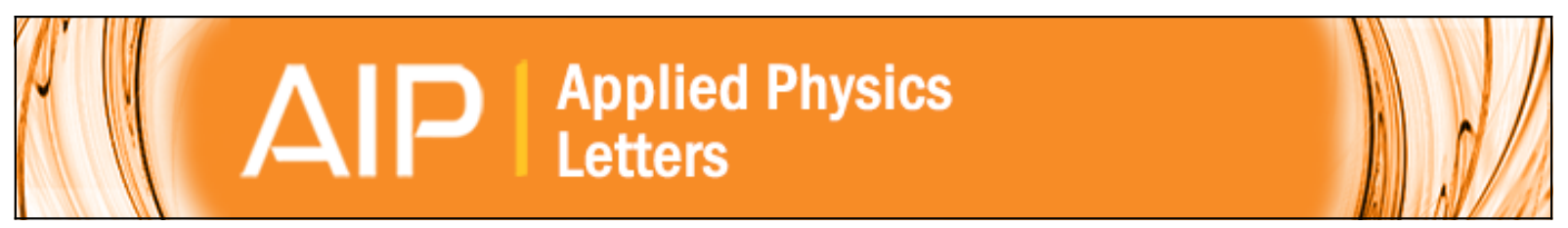

\section{Optical and electrical properties of polycrystalline and amorphous Al-Ti thin films}

S. Canulescu, C. N. Borca, K. Rechendorff, S. Daviðsdóttir, K. Pagh Almtoft, L. P. Nielsen, and J. Schou

Citation: Applied Physics Letters 108, 141909 (2016); doi: 10.1063/1.4945769

View online: http://dx.doi.org/10.1063/1.4945769

View Table of Contents: http://scitation.aip.org/content/aip/journal/apl/108/14?ver=pdfcov

Published by the AIP Publishing

\section{Articles you may be interested in}

Structure and optical properties of aSiAl and aSiAlHx magnetron sputtered thin films

APL Mater. 4, 036103 (2016); $10.1063 / 1.4944506$

Morphology-induced plasmonic resonances in silver-aluminum alloy thin films

Appl. Phys. Lett. 99, 041116 (2011); 10.1063/1.3619840

Optical properties and local bonding configurations of hydrogenated amorphous silicon nitride thin films J. Appl. Phys. 100, 073516 (2006); 10.1063/1.2356915

Properties of amorphous $\mathrm{Al}-\mathrm{Yb}$ alloy coating for scanning near-field optical microscopy tips

J. Appl. Phys. 92, 6895 (2002); 10.1063/1.1518762

Effect of sputtering with hydrogen dilution on fluorine concentration of low hydrogen content fluorinated amorphous carbon thin films with low dielectric constant

J. Appl. Phys. 86, 2468 (1999); 10.1063/1.371078

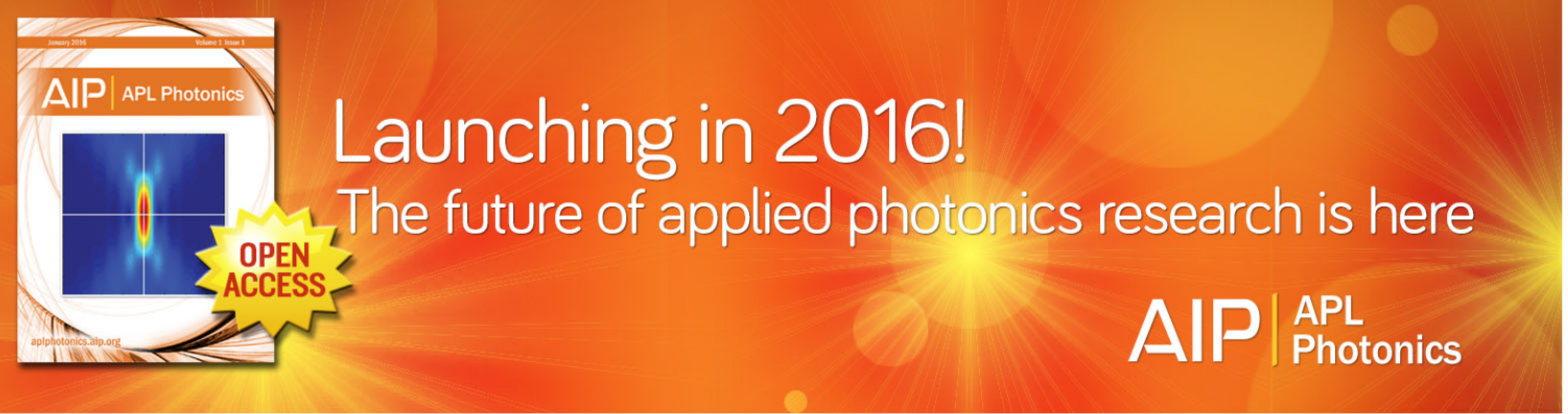




\title{
Optical and electrical properties of polycrystalline and amorphous Al-Ti thin films
}

\author{
S. Canulescu, ${ }^{1}$ C. N. Borca, ${ }^{2}$ K. Rechendorff, ${ }^{3}$ S. Daviðsdóttir, ${ }^{4}$ K. Pagh Almtoft, ${ }^{3}$ \\ L. P. Nielsen, ${ }^{3}$ and J. Schou ${ }^{1}$ \\ ${ }^{1}$ Department of Photonics Engineering, Technical University of Denmark, 4000 Roskilde, Denmark \\ ${ }^{2}$ Paul Scherrer Institute, 5232 Villigen, Switzerland \\ ${ }^{3}$ Danish Technological Institute, 8000 Århus, Denmark \\ ${ }^{4}$ Department of Mechanical Engineering, Technical University of Denmark, 2800 Lyngby, Denmark
}

(Received 29 January 2016; accepted 29 March 2016; published online 7 April 2016)

\begin{abstract}
The structural, optical, and transport properties of sputter-deposited Al-Ti thin films have been investigated as a function of Ti alloying with a concentration ranging from $2 \%$ to $46 \%$. The optical reflectivity of Al-Ti films at visible and near-infrared wavelengths decreases with increasing Ti content. Xray absorption fine structure measurements reveal that the atomic ordering around $\mathrm{Ti}$ atoms increases with increasing Ti content up to $20 \%$ and then decreases as a result of a transition from a polycrystalline to amorphous structure. The transport properties of the Al-Ti films are influenced by electron scattering at the grain boundaries in the case of polycrystalline films and static defects, such as antisite effects and vacancies in the case of the amorphous alloys. The combination of Ti having a real refractive index $(n)$ comparable with the extinction coefficient $(k)$ and $\mathrm{Al}$ with $\mathrm{n}$ much smaller than $\mathrm{k}$ allows us to explore the parameter space for the free-electron behavior in transition metal-Al alloys. The free electron model, applied for the polycrystalline Al-Ti films with Ti content up to 20\%, leads to an optical reflectance at near infrared wavelengths that scales linearly with the square root of the electrical resistivity. C 2016 AIP Publishing LLC. [http://dx.doi.org/10.1063/1.4945769]
\end{abstract}

Much attention has been paid to the prediction and measurements of optical reflectivity of metallic films due to their use in a wide variety of applications ranging from solar reflectors to reflector layers on recordable or erasable-rewritable compact discs. Aluminum is an attractive material due to its high reflectivity, and tailoring its electrical resistivity can be achieved by adding metallic impurities (alloying). Alloying with transition metals (TMs), such as Ti, has turned out to diminish premature fatigue issues associated with stress, as well as enhancing the corrosion resistance and the hardness compared to pure Al. ${ }^{1,2}$ Amorphous Al-Ti alloys exhibit a higher resistance against pitting corrosion compared to the crystalline counterpart. ${ }^{3}$ In aluminum alloys containing transition metals, there will be an s-d electron scattering contribution to the residual resistivity ${ }^{4}$ which also depends upon atomic ordering of the alloys. It is thus important to investigate changes in optical reflectance of metallic alloys as a function of electrical resistivity.

The reflectance of a material can be expressed as

$$
R=1-\frac{4 n}{(n+1)^{2}+k^{2}},
$$

where $n, k$ are the real and imaginary parts of the refractive index, respectively. In near-infrared region when $n(\omega)$ $\ll k(\omega)$, the reflectance can be approximated by the simple expression:

$$
R \approx 1-4 \frac{n}{k^{2}} .
$$

Eq. (2) can be further expressed in terms of the material constants $\tau, \mu$, and $\rho$, where $\tau$ is the electron scattering time, $\mu$ is the magnetic permeability, and $\rho$ is the specific electrical resistivity: ${ }^{5}$

$$
R \approx 1-2 c^{-1} \mu^{-1 / 2} \tau^{-1 / 2} \rho^{1 / 2} .
$$

The free electron model was previously used to correlate optical reflectance with electrical resistivity of multi-component sputtered alloys, such as $\mathrm{AgMgAl}^{5,6}$ and $\mathrm{Al}-\mathrm{Ni}-\mathrm{Y}$ metallic glasses. ${ }^{7}$ The aim of the paper is to investigate the role of Ti alloying on the structural, transport, and optical properties of the sputter-deposited Al thin films. The correlation between the optical reflectivity and electrical resistivity of the Al-Ti alloys will be discussed based on the Drude electron model.

The Al-Ti alloy thin films were deposited by DC magnetron sputtering using two high purity targets of $\mathrm{Al}(99.99 \%)$ and $\mathrm{Ti}(99.99 \%)$. The film composition was varied by changing the relative power on the $\mathrm{Al}$ and Ti targets. The Ar pressure during deposition was $185 \mathrm{mPa}$. The distance between the targets and sample was about $100 \mathrm{~mm}$, and the bias voltage on the substrate was fixed at $-60 \mathrm{~V}$. The substrate temperature during deposition was between 70 and $100^{\circ} \mathrm{C}$. The composition of the films was determined by Rutherford Backscattering Spectrometry (RBS) and Energy Dispersive $\mathrm{X}$-ray Spectroscopy (EDX), and the thickness of the films was measured by profilometry. The crystal structure was determined by grazing incidence X-ray diffraction (GI-XRD). The sheet resistance $\left(R_{S}\right)$ was measured by a four-point probe system, and the electrical resistivity $\rho$ was subsequently calculated as $R_{s} \times d$, where $d$ is the film thickness. The total reflectivity was measured with an integrating sphere system over the wavelength range from 400 to $990 \mathrm{~nm}$. A detailed description of the setup is given elsewhere. ${ }^{8}$ The local structure around $\mathrm{Ti}$ atoms was investigated by Extended X-ray Absorption 
Fine Structure (EXAFS) spectroscopy at $\mathrm{Ti}$ K-edge $(\sim 4966 \mathrm{eV})$ at the microXAS beamline, Swiss Light Source, Switzerland. The spectra were recorded at room temperature, using an X-ray beam size of $1.0 \times 0.6 \mathrm{~mm}^{2}$, delivered by the $\mathrm{Si}$ (111) monochromator crystals with an energy resolution of $\sim 0.3 \mathrm{eV}$. The samples have been measured in fluorescence mode, with a single-element solid state detector (from Ketek) with $180 \mathrm{eV}$ energy resolution. The X-ray absorption data were analyzed following standard procedures using the Demeter software package. ${ }^{9}$

X-ray diffraction (XRD) patterns of representative sputter-deposited Al-Ti thin films with Ti content ranging from $2 \%$ to $46 \%$ are shown in Fig. 1. All films have a thickness of about $110 \pm 20 \mathrm{~nm}$. For the films with a Ti content varying from $2 \%$ to $15 \%$, only the $\mathrm{Al}$ fcc phase is observed, with intense reflections along the (111) and (200) directions indicating a polycrystalline structure. The solubility of $\mathrm{Ti}$ in $\mathrm{Al}$ is about $1.3 \%$ in thermal equilibrium. ${ }^{10}$ The detection of a single $\mathrm{Al}$ fcc phase suggests that $\mathrm{Ti}$ atoms occupy regular positions in the $\mathrm{Al}$ fcc lattice. The XRD diffraction peaks broaden with increasing Ti content suggesting a decrease of the grain size. Indeed, the grain size estimated from the full width at half maximum of the (111) reflection of the A1 fcc phase is 33, 27, and $17 \mathrm{~nm}$ for Al-Ti film with Ti content of $2 \%, 5 \%$, and $15 \%$, respectively. The data indicate that $\mathrm{Ti}$ acts as an efficient grain refiner in the $\mathrm{Al}$ alloys, which is in agreement with previous findings. ${ }^{11,12}$ For the $\mathrm{Al}_{80} \mathrm{Ti}_{20}$ film, the intensity of the peaks increases significantly again and shifts to higher $2 \theta$ values, while the grain size is estimated to be around $27 \mathrm{~nm}$. The shift cannot be associated with the formation of the $\mathrm{Al}_{3}$ Ti phase typically observed at higher $2 \theta$ values. The crystal structure is probably associated with the formation of an ordered $\mathrm{Al}_{1-\mathrm{x}} \mathrm{Ti}_{\mathrm{x}}$ metastable phase. Films with $\mathrm{Ti}$ content of $24 \%$ and above have broad diffraction peaks characteristic of an amorphous structure. Our data are consistent with previous findings of thin films of sputterdeposited Al-Ti alloys to become amorphous at large Ti concentrations. ${ }^{13}$ EXAFS spectroscopy at the Ti K-edge was used to investigate the local structure around the $\mathrm{Ti}$ atoms. The experimental data in Fig. 2 (shown with points) that aligned with the model (shown with lines) involved analysis of

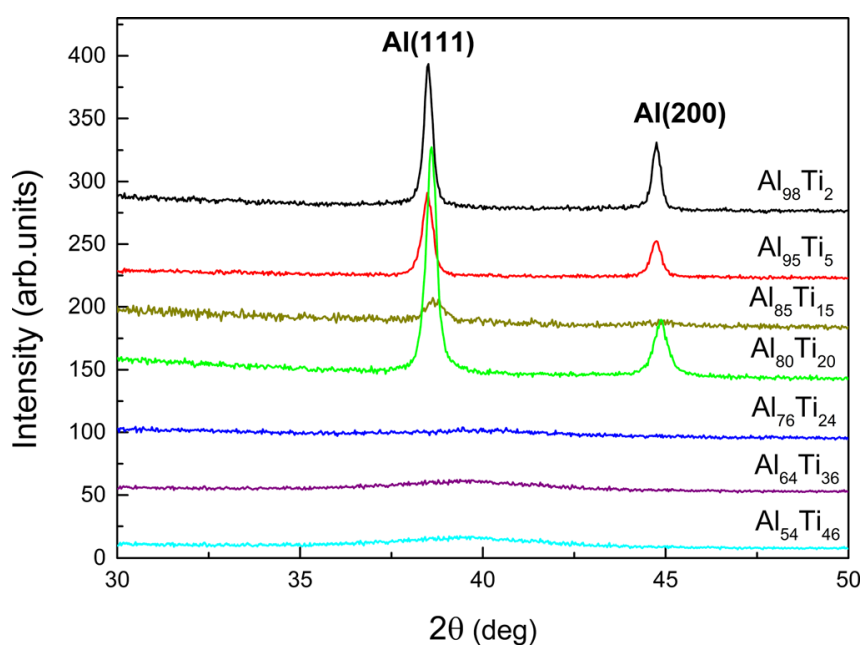

FIG. 1. Grazing incidence X-ray diffraction (GI-XRD) patterns of representative $\mathrm{Al}_{1-\mathrm{x}} \mathrm{Ti}_{\mathrm{X}}(\mathrm{x}=2 \%$ to $46 \%)$ films deposited on glass.
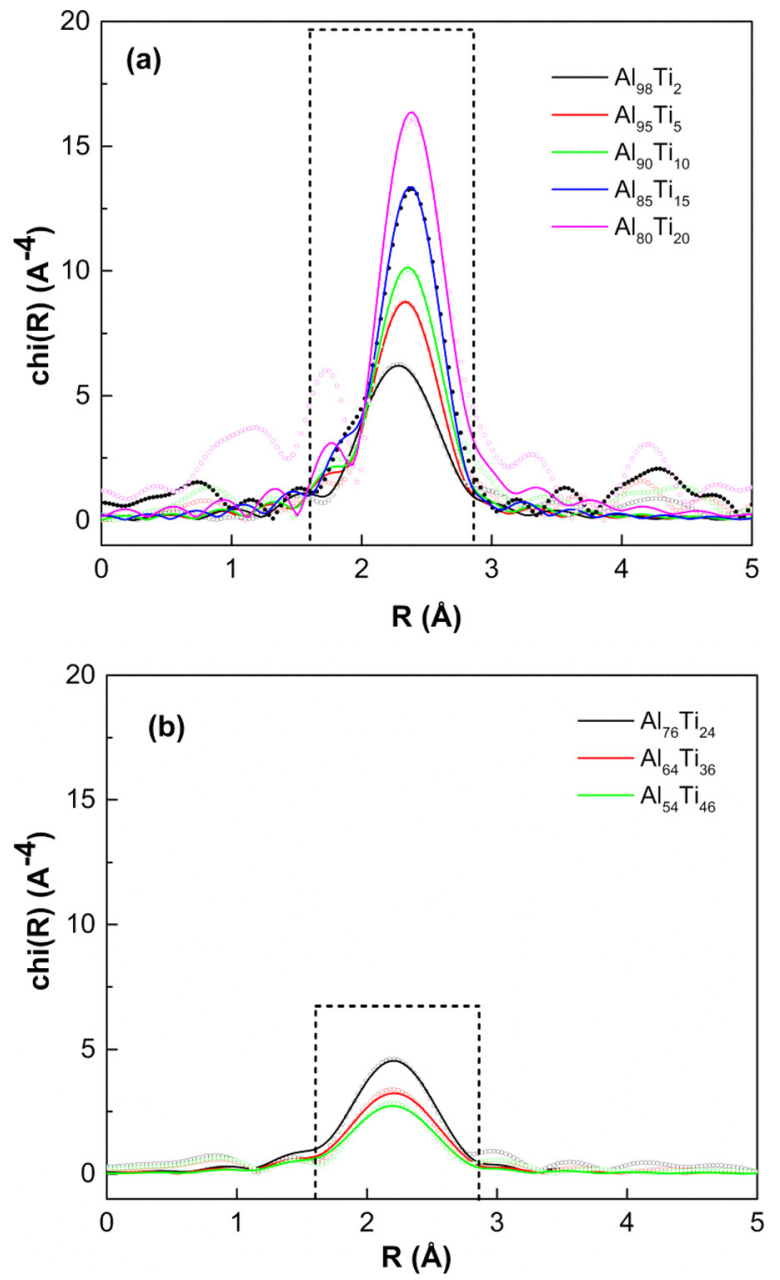

FIG. 2. Fourier-transforms EXAFS spectra measured at the Ti K-edge for $\mathrm{Al}_{1-\mathrm{x}} \mathrm{Ti}_{\mathrm{x}}$ polycrystalline (a) and amorphous alloys (b). The measured data are plotted with points, while the fits are shown with continuous line. The dashed line represents the first shell window used for fitting.

the first Ti-Al shell situated at $2.69 \AA$ in the fcc crystal structure. The Fourier transformed (FT) EXAFS spectra are shown in Figs. 2(a) and 2(b), and the derived structural parameters, such as the coordination number ( $\mathrm{NN})$, distance to the nearest neighbors (R), and Debye Waller factor $\sigma_{0}{ }^{2}$ (which includes a static disorder and thermal vibrations), are given in Table I. As observed in Fig. 2(a), the amplitude of the FT peak corresponding to the polycrystalline alloys $\left(\mathrm{Al}_{1-\mathrm{x}} \mathrm{Ti}_{\mathrm{x}}, \mathrm{x}\right.$ up to $\left.20 \%\right)$ increases with increasing $\mathrm{Ti}$ content and reaches a maximum for $\mathrm{Al}_{80} \mathrm{Ti}_{20}$ (Fig. 2(a)). Consequently, the Debye Waller factor decreases suggesting an increase of the structural ordering around $\mathrm{Ti}$ atoms. The lowest $\sigma_{0}^{2}$ value was obtained for the $\mathrm{Al}_{80} \mathrm{Ti}_{20}$ film which indicates a highly ordered phase. In contrast, the amplitude of the peak corresponding to the amorphous alloys $\left(\mathrm{Al}_{1-\mathrm{x}} \mathrm{Ti}_{\mathrm{x}}\right.$, $\mathrm{x}$ of $25 \%$ and above) drops significantly compared to the crystalline counterpart (Fig. 2(b)). The $\sigma_{0}{ }^{2}$ values are larger compared to the crystalline alloys, while the NN is significantly reduced, suggesting that the disorder around $\mathrm{Ti}$ atoms is significantly higher compared to the crystalline counterpart. ${ }^{14,15}$ Amorphous alloys have a lower coordination number and smaller average inter-atomic distance compared to the crystalline counterpart, and this trend is more pronounced for $\mathrm{Al}_{46} \mathrm{Ti}_{64}$ and $\mathrm{Al}_{54} \mathrm{Ti}_{46}$ (see Table I). The trend can result from an increased sp-d hybridization, ${ }^{16}$ perhaps as a 
TABLE I. List of investigated sputter-deposited Ti, Al, and Al-Ti thin films showing the results from XRD, EXAFS, resistivity, and optical reflectance. $\mathrm{NN}=$ number of nearest neighbors in the first coordination shell at distance R from the Ti atoms; $\sigma_{0}{ }^{2}$ is the Debye-Waller factors obtained from EXAFS fitting.

\begin{tabular}{|c|c|c|c|c|c|c|}
\hline \multirow[b]{2}{*}{ Films composition } & \multirow[b]{2}{*}{ Crystal structure } & \multicolumn{3}{|c|}{ EXFAS } & \multirow[b]{2}{*}{ Resistivity $(\mu \Omega \times \mathrm{cm})$} & \multirow[b]{2}{*}{ Optical reflectance at $980 \mathrm{~nm}$} \\
\hline & & NN & Interatomic distance $\mathrm{R}(\AA)$ & $\sigma_{0}^{2}\left(\AA^{-2}\right)$ & & \\
\hline $\mathrm{Al}_{98} \mathrm{Ti}_{2}$ & Polycrystalline & 3.5 & $2.78 \pm 0.014$ & $0.010 \pm 0.002$ & 32 & 0.85 \\
\hline $\mathrm{Al}_{95} \mathrm{Ti}_{5}$ & Polycrystalline & 4 & $2.79 \pm 0.01$ & $0.008 \pm 0.001$ & 66 & 0.82 \\
\hline $\mathrm{Al}_{90} \mathrm{Ti}_{10}$ & Polycrystalline & 4.5 & $2.80 \pm 0.007$ & $0.0078 \pm 0.001$ & 70 & 0.69 \\
\hline $\mathrm{Al}_{85} \mathrm{Ti}_{15}$ & Polycrystalline & 5.3 & $2.80 \pm 0.005$ & $0.007 \pm 0.001$ & 91 & 0.64 \\
\hline $\mathrm{Al}_{80} \mathrm{Ti}_{20}$ & Polycrystalline & 5.1 & $2.82 \pm 0.014$ & $0.003 \pm 0.002$ & 121 & 0.62 \\
\hline $\mathrm{Al}_{76} \mathrm{Ti}_{24}$ & Amorphous & 3.9 & $2.75 \pm 0.064$ & $0.016 \pm 0.012$ & 186 & 0.6 \\
\hline $\mathrm{Al}_{64} \mathrm{Ti}_{36}$ & Amorphous & 3.04 & $2.76 \pm 0.029$ & $0.018 \pm 0.005$ & 219 & 0.55 \\
\hline $\mathrm{Al}_{54} \mathrm{Ti}_{46}$ & Amorphous & 2.43 & $2.74 \pm 0.034$ & $0.017 \pm 0.006$ & 278 & 0.52 \\
\hline Sputter deposited Al & $\ldots$ & $\ldots$ & $\ldots$ & $\ldots$ & 26 & 0.88 \\
\hline Sputter deposited $\mathrm{Ti}$ & $\ldots$ & $\ldots$ & $\ldots$ & $\ldots$ & 150 & 0.39 \\
\hline
\end{tabular}

result of increase of the covalent bonding nature of the alloys. ${ }^{17-19}$

The electrical resistivity of the Al-Ti films increases with Ti content, as shown in Fig. 3. In Aluminium alloyed with transition metals, there will also be an sp-d electron scattering contribution to the resistivity. ${ }^{4,20,21}$ Polycrystalline Al-Ti films of a single fcc structure (Ti content up to $15 \%$ ) consist of nanoscale grains that decrease in size with increasing Ti content. Consequently, the electrical resistivity increases as a result of enhanced electron scattering at the grain boundaries. For a Ti content of $20 \%$ and above, the electrical resistivity of the films is larger than $100 \mu \Omega \times \mathrm{cm}$. The origin of the high resistivity of the $\mathrm{Al}_{80} \mathrm{Ti}_{20}$ ordered phase needs to be further studied. Mooij et al. ${ }^{22}$ have indicated that in materials with high electrical resistivity ( $>100 \mu \Omega \times \mathrm{cm}$ ), the mean free path of the conduction electrons is of the order of the short range order of the materials. The large electrical resistivity values of the amorphous films can probably be associated with scattering of conduction electrons by $3 \mathrm{~d}-\mathrm{Ti}$ metal ions at $\mathrm{Al}$-site and vacancies $\left(\mathrm{V}_{\mathrm{Ti}} \text { or } \mathrm{V}_{\mathrm{Al}}\right)^{18}$ rather than microscopic defects, such as grain boundaries.

The optical reflectance spectra of $\mathrm{Al}_{1-\mathrm{x}} \mathrm{Ti}_{\mathrm{x}}$ alloys at visible and near infrared wavelengths are shown in Fig. 4. Upon alloying, optical reflectance decreases gradually with

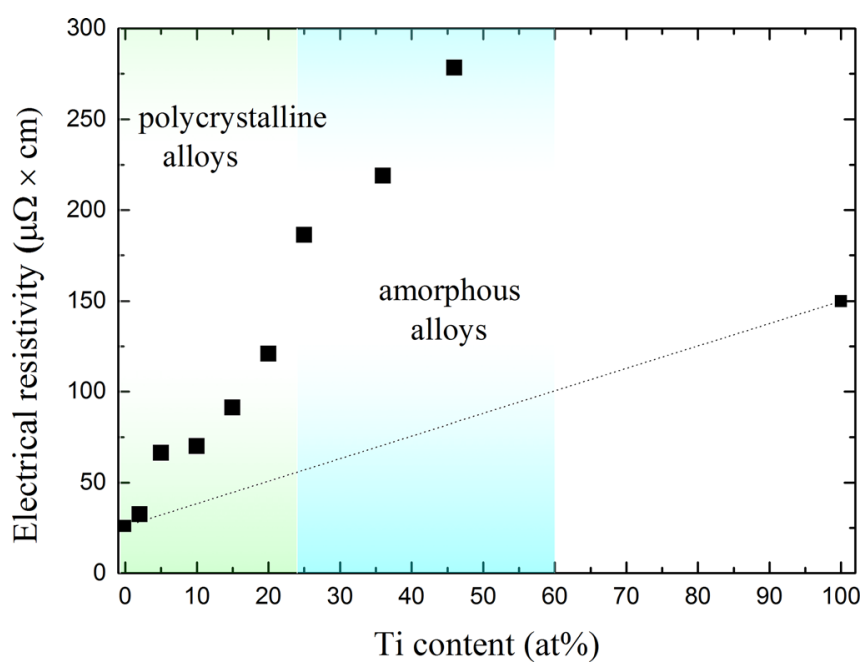

FIG. 3. Electrical resistivity of the sputter-deposited Al, Ti, and Al-Ti films with Ti content varying from $2 \%$ to $46 \%$. increasing Ti content, both at visible and near infrared wavelengths. Pure $\mathrm{Al}$ has a high reflectance in the visible and near infrared spectral range and exhibits a reflectivity drop at around $800 \mathrm{~nm}$ due to intraband transitions, ${ }^{23}$ as shown in the inset in Fig. 4. Low Ti alloying ( 2 and 5 at. \% Ti) results in a significant weakening of the intraband transitions and shift of the position of the peak towards higher photon energy. For Ti content of 10 at. $\%$ and above, the reflectance spectra decrease significantly and the absorption peak associated with the intraband absorption vanishes. The disappearance of the absorption dip for Ti content above 10\% indicates that the band structure of $\mathrm{Al}$ is significantly affected by $\mathrm{Ti} 3 \mathrm{~d}$ impurities. Amorphous alloys have a relatively flat optical reflectivity profile over the entire wavelength. We have used the free-electron model to study the relationship between optical reflectance at nearinfrared wavelengths and transport properties of the Al-Ti alloys according to Eq. (3). We assume that the magnetic permeability is constant for non-ferromagnetic materials, such as pure $\mathrm{Al}$ and $\mathrm{Ti}$, and does not vary significantly over the studied composition range. Aluminum alloys with dilute concentration of $\mathrm{Cr}, \mathrm{Mn}$, or Fe were found to be magnetic ${ }^{20,24,25}$ but non-magnetic in case of $\mathrm{Ti}^{26}$ The optical reflectance depends mainly on the electrical resistivity $(\rho)$ and the electron

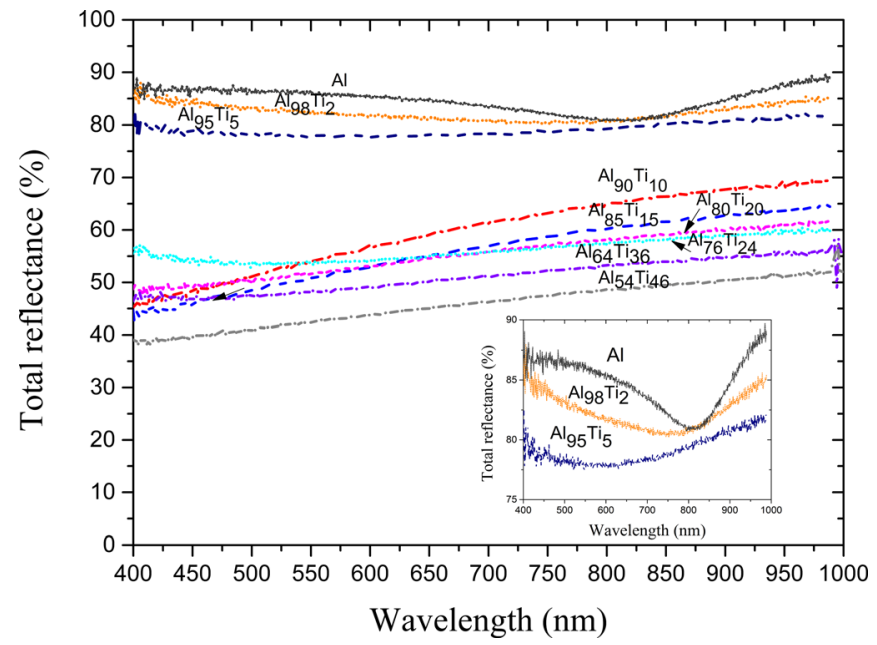

FIG. 4. Spectrally resolved total reflectance of poly-crystalline and amorphous Al-Ti alloys. Inset: optical intraband transition in sputter-deposited $\mathrm{Al}, 2 \%$ and $5 \%$ Ti-alloyed $\mathrm{Al}$ films. 


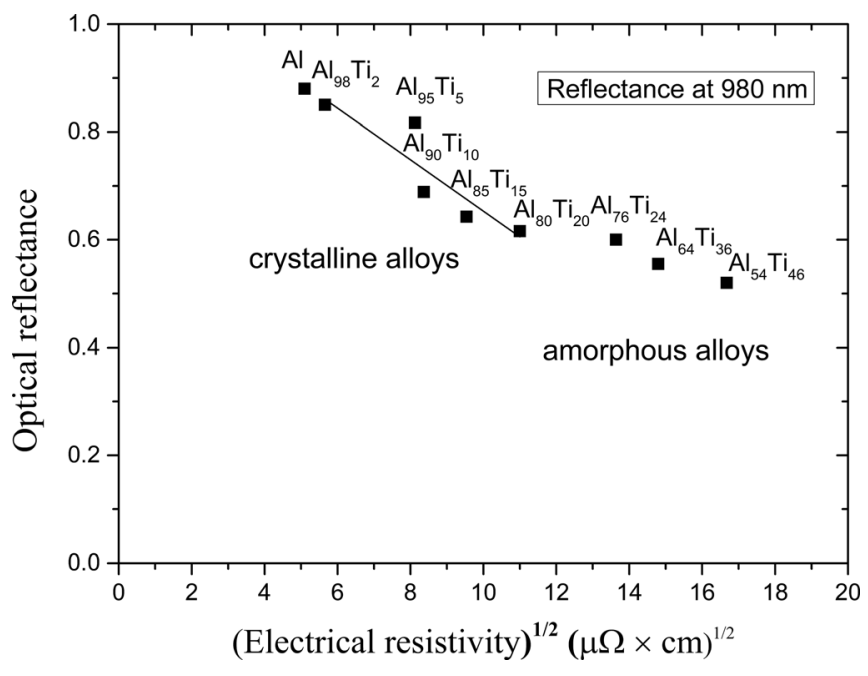

FIG. 5. Optical reflectivity of the crystalline and amorphous Al-Ti alloys at $980 \mathrm{~nm}$ as a function of square root of the electrical resistivity. The linear fit of the reflectivity $\mathrm{R}$ versus $\rho^{1 / 2}$ corresponds to the polycrystalline alloys with Ti content varying from $2 \%$ to $20 \%$.

scattering time $(\tau)$. Optical reflectance of the Al-Ti alloys as a function of the square root of the electrical resistivity is plotted in Fig. 5. The data are also given in Table I. The wavelength of $980 \mathrm{~nm}$ was chosen as it corresponds to a region where the reflectivity reaches a nearly steady state regime. It is worthwhile mentioning that at near infrared wavelengths, $n$ $\sim k$ for pure Ti and $n \ll k$ for pure $\mathrm{Al}^{27}$ Obviously, there will be a limit for which the Al-Ti alloyed system can satisfy Eq. (3). The data in Fig. 5 include pure Al, polycrystalline, and amorphous Al-Ti alloys. Note that pure Ti does not satisfy Eq. (3). Polycrystalline Al-Ti alloys have a high fraction of grain boundaries that increases with smaller grains, and thus it is expected to have a larger electrical resistivity compared to pure Al. Amorphous Al-Ti films have a larger offset compared to their polycrystalline counterpart, while their transport properties are governed by scattering of conduction electrons by anti-site effects and vacancies. EXAFS data indicate that amorphous alloys with large $\mathrm{Ti}$ content $\left(\mathrm{Al}_{46} \mathrm{Ti}_{64}\right.$ and $\mathrm{Al}_{54} \mathrm{Ti}_{46}$ ) have a more pronounced covalently bonded environment. Strong hybridization between sp-d electron states leads to a lower free electron density. ${ }^{28}$ Consequently, the Drude electron model was only used to describe the linear dependence between the optical reflectance and the square root of the electrical resistivity for the polycrystalline Al-Ti films (see Fig. 5).

In summary, the optical and electrical properties of Al-Ti alloys deposited by sputtering have been investigated. Structural analysis indicates that the Al fcc structure is preserved in the alloyed films with a Ti content up to $15 \%$, following by the appearance of a metastable phase at a $\mathrm{Ti}$ content $20 \% \mathrm{Ti}$ and finally transformation to an amorphous structure. EXAFS indicates that structural disorder around $\mathrm{Ti}$ atoms is consequently greatly enhanced in the amorphous alloys, while the coordination number and inter-atomic distance are slightly reduced as a result of enhanced covalently bonding environment. The transport properties of polycrystalline films depend strongly on the microstructure of the films (grain boundaries), while in the case of amorphous alloys, the scattering of the conduction electrons is determined by static imperfections (anti-site effects and vacancies). Optical reflectance of the polycrystalline Al-Ti films at near infrared wavelengths scales linearly with the square root of the electrical resistivity according to the classical reflection theory.

The authors would like to thank the Danish National Advanced Technology Foundation for the financial support. The authors would also like to thank Dr. Jui-Hong Hsu for kindly having provided us with information about the analysis in Ref. 5.

${ }^{1}$ K. Hashimoto, N. Kumagai, H. Yoshioka, H. Habazaki, A. Kawashima, K. Asami, and B.-P. Zhang, in Rapidly Quenched Materials, edited by $\mathrm{H}$. Frederikssons Savage (Elsevier, Oxford, 1991), pp. 22-25.

${ }^{2}$ J. C. Oliveira, A. Cavaleiro, and M. T. Vieira, Surf. Coat. Technol. 151-152, 466 (2002).

${ }^{3}$ K. Hashimoto, N. Kumagai, H. Yoshioka, J. H. Kim, E. Akiyama, H. Habazaki, S. Mrowec, A. Kawashima, and K. Asami, Corros. Sci. 35, 363 (1993).

${ }^{4}$ P. L. Rossiter and P. Wells, J. Phys., Part C 4, 354 (1971).

${ }^{5}$ T. T. Hu, J. H. Hsu, J. C. Huang, S. Y. Kuan, C. J. Lee, and T. G. Nieh, Appl. Phys. Lett. 101, 011902 (2012).

${ }^{6}$ W. H. Wang, J. H. Hsu, and J. C. Huang, Appl. Phys. Lett. 103, 161906 (2013).

${ }^{7}$ C. M. Chang, C. H. Wang, J. H. Hsu, and J. C. Huang, Thin Solid Films 571(Part 1), 194 (2014).

${ }^{8}$ S. Daviðsdóttir, J. Soyama, Kai Dirscherl, S. Canulescu, J. Schou, and R. Ambat, Surf. Coat. Technol. 216, 35 (2013).

${ }^{9}$ B. Ravel and M. Newville, J. Synchrotron Radiation 12, 537 (2005).

${ }^{10} \mathrm{H}$. W. Woltgens, I. Friedrich, W. K. Njoroge, W. Theiss, and M. Wuttig, Thin Solid Films 388, 237 (2001).

${ }^{11}$ T. V. Atamanenko, D. G. Eskin, M. Sluiter, and L. Katgerman, J. Alloys Compd. 509, 57 (2011).

${ }^{12}$ K. B. Hyde, A. F. Norman, and P. B. Prangnell, Aluminum Alloys 2002: their Physical and Mechanical Properties Pts 1-3, 396-4, 39 (2002).

${ }^{13}$ H. C. Kim, N. D. Theodore, K. S. Gadre, J. W. Mayer, and T. L. Alford, Thin Solid Films 460, 17 (2004).

${ }^{14}$ J. Ströhr, NEXAFS spectroscopy (Springer, 1992).

${ }^{15}$ J. J. Rehr and R. C. Albers, Rev. Mod. Phys. 72, 621 (2000).

${ }^{16}$ Y. Liu, G. Schumacher, I. Zizak, A. Erko, and J. Banhart, Mater. Lett. 70, 171 (2012).

${ }^{17}$ K. Lie, R. Holmestad, K. Marthinsen, and R. Hoier, Phys. Rev. B 57, 1585 (1998).

${ }^{18}$ Y. Shirai, K. Masaki, T. Inoue, S. R. Nishitani, and M. Yamaguchi, Intermetallics 3, 381 (1995).

${ }^{19}$ H. J. Chang, L. F. Chen, and X. F. Zhu, J. Phys. D 46, 105303 (2013).

${ }^{20}$ M. Mantina, S. L. Shang, Y. Wang, L. Q. Chen, and Z. K. Liu, Phys. Rev. B 80, 184111 (2009).

${ }^{21}$ P. L. Rossiter, J. Phys. F 10, 1459 (1980).

${ }^{22}$ J. H. Mooij, Phys. Status Solidi A 17, 521 (1973).

${ }^{23}$ H. V. Nguyen, I. An, and R. W. Collins, Phys. Rev. B 47, 3947 (1993).

${ }^{24}$ B. V. Reddy, P. Jena, and S. C. Deevi, Intermetallics 8, 1197 (2000).

${ }^{25}$ Y. P. Lee, Y. V. Kudryavtsev, V. V. Nemoshkalenko, J. Y. Rhee, and K. W. Kim, J. Appl. Phys. 91, 4364 (2002).

${ }^{26}$ P. Terzieff and J. Auchet, J. Phys.-Condens. Matter 10, 4139 (1998).

${ }^{27}$ M. N. Polyanskiy, Refractive index database, 2016.

${ }^{28}$ W. Deng, D. K. Xiong, J. Y. Wang, L. Y. Xiong, M. Z. Cao, and C. W. Lung, J. Mater. Sci. Technol. 19, 164 (2003). 